J. Asiat. Soc. Bangladesh, Sci. 44(2): 101-115, December, 2018

\title{
WILDLIFE DIVERSITY AND POPULATION STATUS OF KASHIMPUR UNION, GAZIPUR, BANGLADESH
}

\author{
NAZMUL ISLAM, M. FIROJ JAMAN ${ }^{*}$, MD. MOKHLESUR RAHMAN \\ AND MD. MAHABUB ALAM \\ Department of Zoology, University of Dhaka, Dhaka -1000, Bangladesh
}

\begin{abstract}
Wildlife diversity (amphibians, reptiles, birds and mammals) of Kashimpur Union in Gazipur Sadar Upazila under Gazipur district was studied from May, 2015 to March, 2016. A total of 110 species of wildlife belonging to 58 families under 19 orders were recorded. Among them, $6(5.45 \%)$ species were amphibians, $14(12.72 \%)$ reptiles, 72 $(65.45 \%)$ birds and $18(16.38 \%)$ were mammals. Among the amphibians, $5(83.33 \%)$ species were frogs and only one $(16.67 \%)$ was toad; of reptiles, $7(50 \%)$ species were lizards, $5(35.71 \%)$ snakes and $2(14.29 \%)$ were tortoises. Of the birds, $39(54.16 \%)$ species were passerines and remaining $33(45.84 \%)$ were non-passerines. Resident status shows that $66(91.62 \%)$ species were resident, $5(7.00 \%)$ migrants and $1(1.38 \%)$ species were vagrant. Among the mammals, $8(44.45 \%)$ species were rodents, $4(22.22 \%)$ flying mammals and $6(33.33 \%)$ species were carnivorous mammals. The relative abundance shows that $10(9.09 \%)$ species were very common, 24 (21.81\%) common, $31(28.19 \%)$ fairly common and $45(40.91 \%)$ species were few. Considering the conservation status, 5 species were near threatened and 105 were the least concern nationally. According to Shannon-Wiener $(H=3.287)$ and Simpson's $(D=0.942)$ diversity indices, diversity of birds was higher than the other wildlife observed. Some potential threats on wildlife diversity were identified such as habitat degradation and fragmentation, expansion of agricultural lands and urbanization. Therefore, conservation and management are necessary in order to protect the diversity of existing wildlife and their population in the study area.
\end{abstract}

Key words: Wildlife diversity, Population status, Relative abundance

\section{Introduction}

Bangladesh has a rich biological heritage of being situated in the subtropical region at the confluence of the Indo-Himalayas and Indo-China sub-regions of the Oriental region (Khan 2008). Unique physiographic characteristics, variations in hydrological and climatic conditions and difference in the soil properties support a diverse set of ecosystems that have enriched the diversity of flora and fauna (Mittermeier et al. 1998, Jaman et al. 2014). Bangladesh is the home of 138 species of mammals (including 11 regionally extinct species), 566 species of birds (including 19 regionally extinct species),

\footnotetext{
*Author for correspondence: E-mail: mfjaman@yahoo.com
} 
167 species of reptiles (including one regionally extinct species) and 49 species of amphibians (IUCN Bangladesh 2015a). Only wild fauna (amphibia to mammalia) of Bangladesh constitute around 3.5\% of the total wildlife in the world (Khan 2008, Jaman et al. 2015).

Biodiversity became the issue of global anxiety over the past few decades for its rapid reduction worldwide and interestingly, the majority of the world's biodiversity is present in most of the economically non-solvent countries like Bangladesh (Koziell 2001). It is widely supposed that the poorest people of the poor countries depend on their local ecosystems for their livelihoods are responsible for the degradation of biodiversity (CBD 2006 and 2007). Widlife plays ecological and economical role in both invertebrate and vertebrate pest control (Jaman et al. 1999), scavenging and pollinating as well as providing food to mankind. The larvae of frogs and toads feed mainly on algae, dead animals in water, diatoms, planktons or other small organisms playing an important role in the ecosystem (Hasan and Feeroz 2014). Unfortunately, the wildlife populations of Bangladesh have been decreasing at an alarming rate mainly due to anthropogenic developmental activities including habitat destruction and fragmentation, water pollution degradation of vegetation, deforestation, conversion of wetlands and forests to agricultural land and conversion of farm-land to urban and industrial uses (Sarker et al. 2000, Hossain et al. 2004, Khan and Ahsan 2011, Karmakar et al. 2011, Rahman et al. 2012, IUCN Bangladesh 2015 b,c,d). To address the role of wildlife in an area, rigorous scientific studies are therefore needed to protect them from their critical positions.

However, some studies have been conducted on avian diversity in different parts of Dhaka city (Hussain et al. 1974, Das 1975, Sarker et al. 2009, Mohsanin and Khan 2009, Akash et al. 2013, Chowdhury et al. 2014, Islam et al. 2014, Jaman et al. 2014, Jaman et al. 2015, Rajia et al. 2015, Banu et al. 2016). No specific study has yet been done on wildlife of Kashimpur Union. Therefore, this study may play a significant role to make baseline information on wildlife diversity in the study area.

\section{Materials and Methods}

The study was conducted in Kashimpur Union of Gazipur district under Dhaka division, situated on the bank of Turag river in between $23^{0} 59^{\prime} 04.94 " \mathrm{~N}$ and $90^{\circ} 19^{\prime} 18.46^{\prime \prime} \mathrm{E}$. It is bounded by Konabari union on the north-east, Basan union on the east, Gachha union on the south-east, Kaliakair Upazila on the north and Savar Upazila in the south. The total area of the union is about $42.32 \mathrm{~km}^{2}$ covered mainly by plain land. A number of ponds, swamps, ditches, canals and beels have enriched the aquatic habitat of the union. 


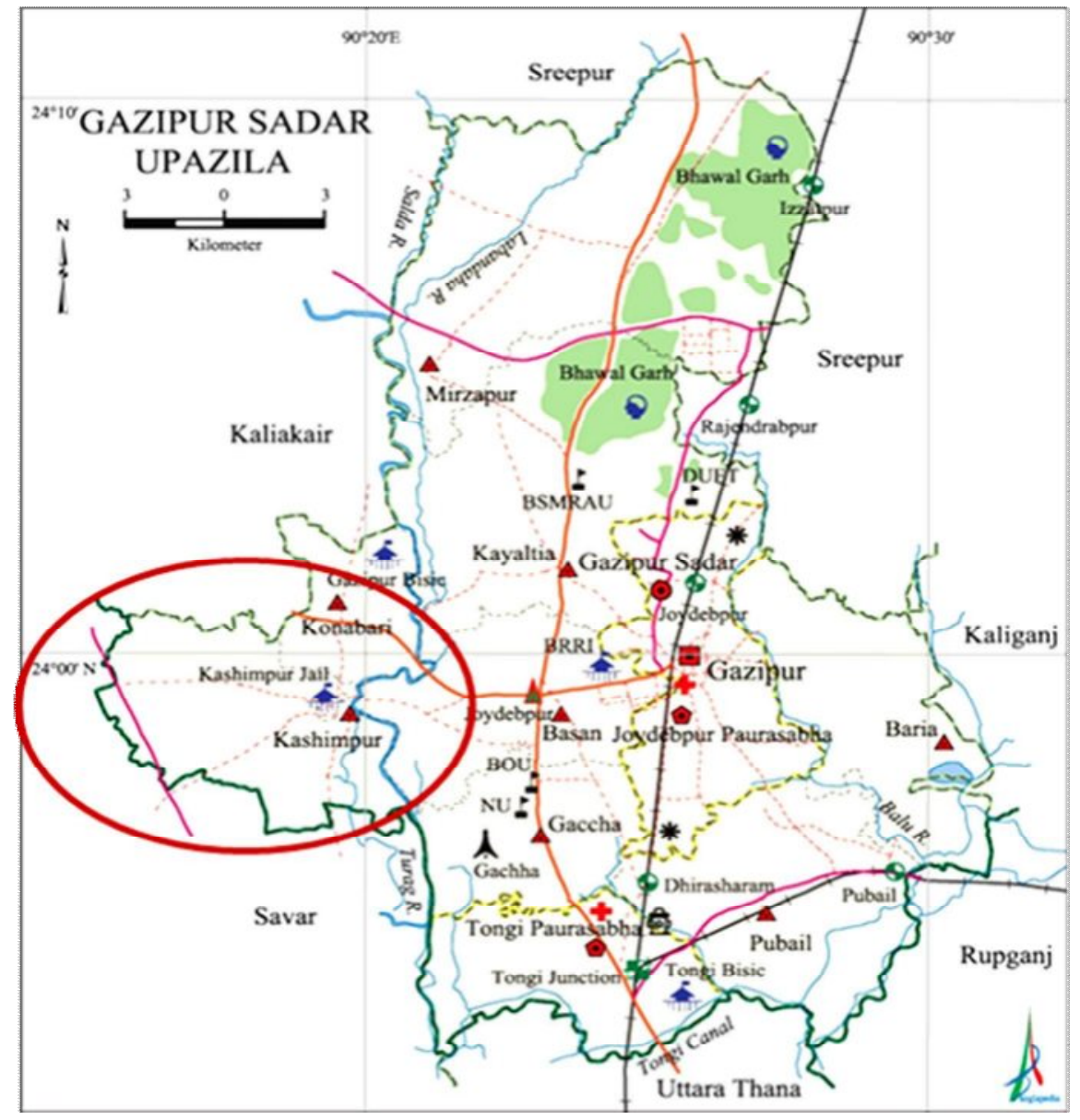

Fig. 1. Gazipur Sadar Upazila map showing Kashimpur Union (Source: Banglapedia 2003).

Observation procedure: Data were collected by direct field observations from May, 2015 to March, 2016. A total of 42 days ( 3 to 4 days per month) were spent in the field for data collection. Observations were started early in the morning and continued till sunset. We also collected data on herpetofauna, nocturnal birds and mammals after sunset since they are mostly active at night. Random sampling was followed to observe nocturnal birds and mammals. During the study period a pair of binoculars (Bushnell Power View $10 \times 42$ ) was used in order to identify bird species from the longer distance. For identification of birds Grimmett et al. (1999), Halder (2010) and Khan (2015) were followed. In many cases birds were photographed with a digital semi-SLR camera (Canon SX 50HS) in order to confirm the identification. Hasan et al. (2014) and Daniel (2002) were followed 
for the identification of herpetofauna. Khan (2008) and Khan (2015) were followed to identify the mammalian fauna. The study period was divided into three seasons, viz. summer (March-June), rainy (July - October) and winter (November-February). The relative abundance was estimated following Khan (1982) as very common (VC): 80 100\%, common (C): 50 - 79\%, fairly common (FC): 20 - 49\% and a few (F): $10-19 \%$. The data were calculated based on total sighting.

The Shannon-Wiener index (1949) and Simpson's index (1949) of diversity and evenness (quantifies how numerically equal the community is) of species in the study area were also calculated using following formulas:

Simpson's index of diversity, $D=l-\operatorname{sum}\left(P_{i}^{2}\right)$

Shannon-Wiener Index, $H=-\operatorname{sum}\left(P_{i} \ln \left[P_{i}\right]\right)$ (natural $\left.\log \right)$

Evenness, $E=H / \ln (S)$ (natural $\log$ ), (where, $P_{i}=$ Number of individuals of a species/ total number of individuals of all species from the same group, and $S=$ Number of species from the same group observed).

Line transect sampling method: The data regarding different species available in the study area were recorded following the transect line sampling method. In every month we followed at least 5 transect lines totalling 60 during the study period. The size of each line was $500 \mathrm{~m}$ length and $50 \mathrm{~m}$ in both sides. When any species was observed, population was counted along with their habitat type and food habit. Microhabitats had been categorized as tree hole, water body, open forest, branches of tree, woody trees, fruiting tress, shrubs, bushes, jungles, crevices, grass field, crop field, store house and house.

Plot counting: Plot counting method was used for estimating amphibian species. A total of 20 plots were selected during the study period for observation of amphibian species. Each plot size was $10 \times 10 \mathrm{~m}^{2}$. We counted every visible individual inside the plot. There might be chances to escape some individuals from the plot and they were not counted.

Calls and songs: Some avifauna and some amphibians, when hidden in the bushes, jungles and branches of trees, were traced by hearing their songs and calls first and later we identified them by visual encounter.

Interviewing local people: All animals were not visible across the study period and nocturnal animals were not easy to observe. In this regard, some questionnaires were distributed among the inhabitants of the study area to gather more information on those wild animal. Local peoples were asked about the presence of species showing their photographs available in the field pictorial guide. 


\section{Results and Discussion}

A total of 110 species of wildlife were observed of which 6 (5.45\%) were amphibians, 14 (12.72\%) reptiles, $72(65.45 \%)$ birds and $18(16.38 \%)$ were mammals. The observed species belong to 58 families under 19 orders (one order of Class Amphibia, 2 of Class Reptilia and 12 of Aves and 4 orders of Class Mammalia) (Tables 1-4).

Faunal composition of observed wildlife: Out of 6 observed amphibian species, only Duttaphrynus melanostictus represents the group toad and other 5 species were frogs (Table 1). The most frequently observed species was common toad (Duttaphrynus melanostictus) with 2.4 indiv. $/ 100 \mathrm{~m}^{2}$ and the least observed was Microhyla ornata $(0.1$ indiv. $\left./ 100 \mathrm{~m}^{2}\right)$.

There were 14 species of reptiles belonging to three groups, viz, lizards, snakes and tortoise. Among them, 7 (50\%) species were lizards, 5 (35.71\%) snakes and 2 (14.29\%) were tortoises. Out of 5 species of snakes, 4 were non-venomous and only one was deadly venomous (Naja naja). The highest density $\left(20.67\right.$ indiv. $/ \mathrm{km}^{2}$ ) was recorded for House Lizard (Hemidactylus flaviviridis) whereas the lowest density $\left(0.33\right.$ indiv. $\left./ \mathrm{km}^{2}\right)$ was for Rat Snake (Ptyas mucosa).

Of the bird species, 39 (54.16\%) were passerines and rest $33(45.84 \%)$ were nonpasserine. The highest density (207.00 indiv. $/ \mathrm{km}^{2}$ ) of bird species was the common Myna (Acredotheres tristis) and the lowest $\left(0.67\right.$ indiv. $\left./ \mathrm{km}^{2}\right)$ was the Dusky Warbler (Phylloscopus fuscatus).

A total of 18 species of mammals were observed in the study area. Of them, 8 (44.45\%) were rodents, $4(22.22 \%)$ flying mammals and $6(33.33 \%)$ were carnivorous mammals. The most frequently observed species was Irrawaddy Squirrel (Callosciurus erythraeus) (30.67 indiv. $/ \mathrm{km}^{2}$ ) and the least observed species were Small Civet (Viverriculla indica) and Jungle Cat (Felis chaus).

The present study observed 110 species of wildlife that depicts the study area could be better home for wildlife as it supports many flowering plants, fruiting trees, shrubs, large trees, tree crevices, bushes, jungles, crop fields and different types of waterbodies.

Monthly variation of species composition: During the study period, there was surprising fluctuation in the species composition. The maximum number of species were recorded in the month of December ( 84 species), followed by January (69 spp.) and November (64 spp.). On the other hand, the minimum number of species was documented in August (only $28 \mathrm{spp}$.); from where there was dramatic increase in the number of species in every month and continued till December. Since the species number has been gradually 


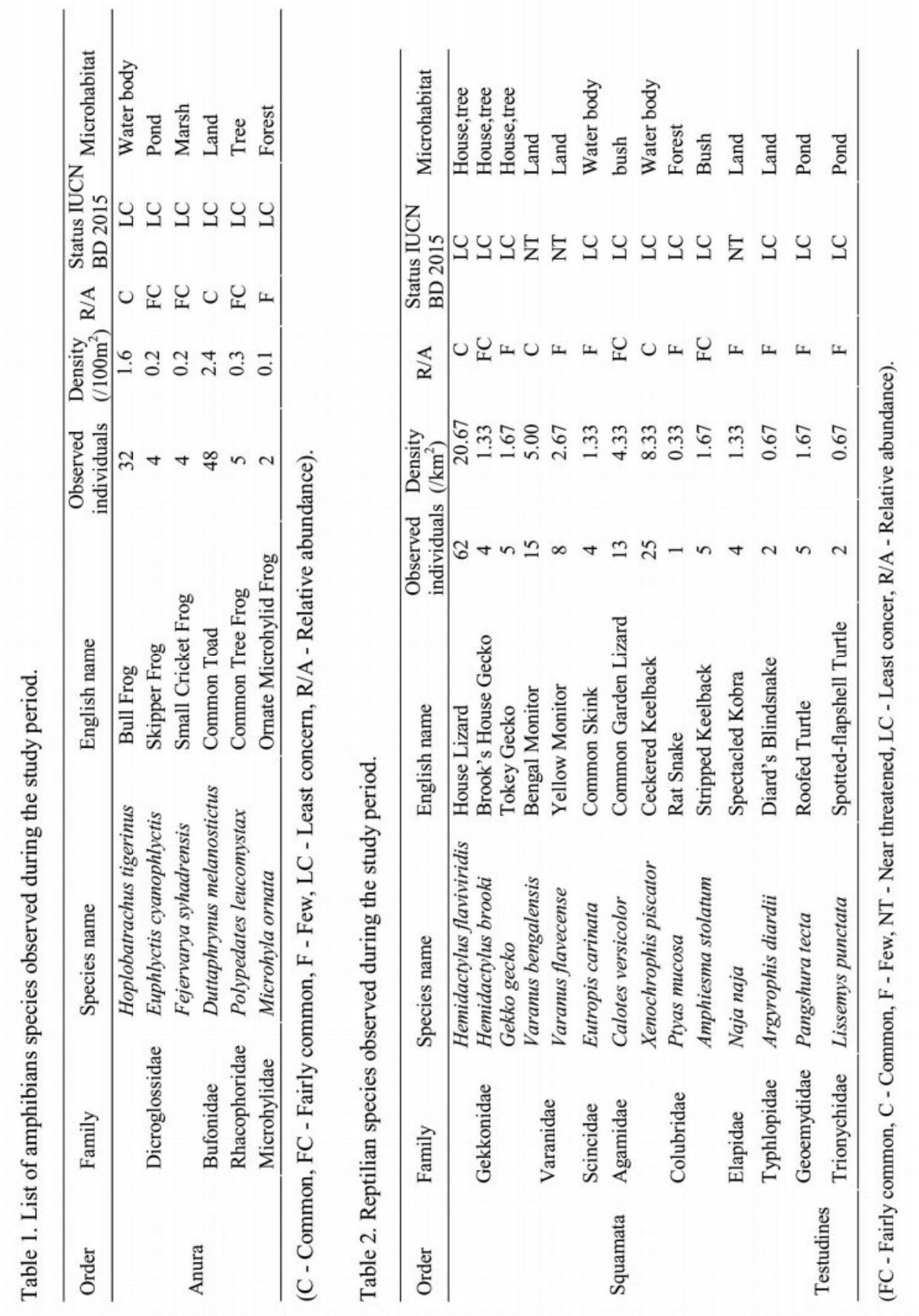




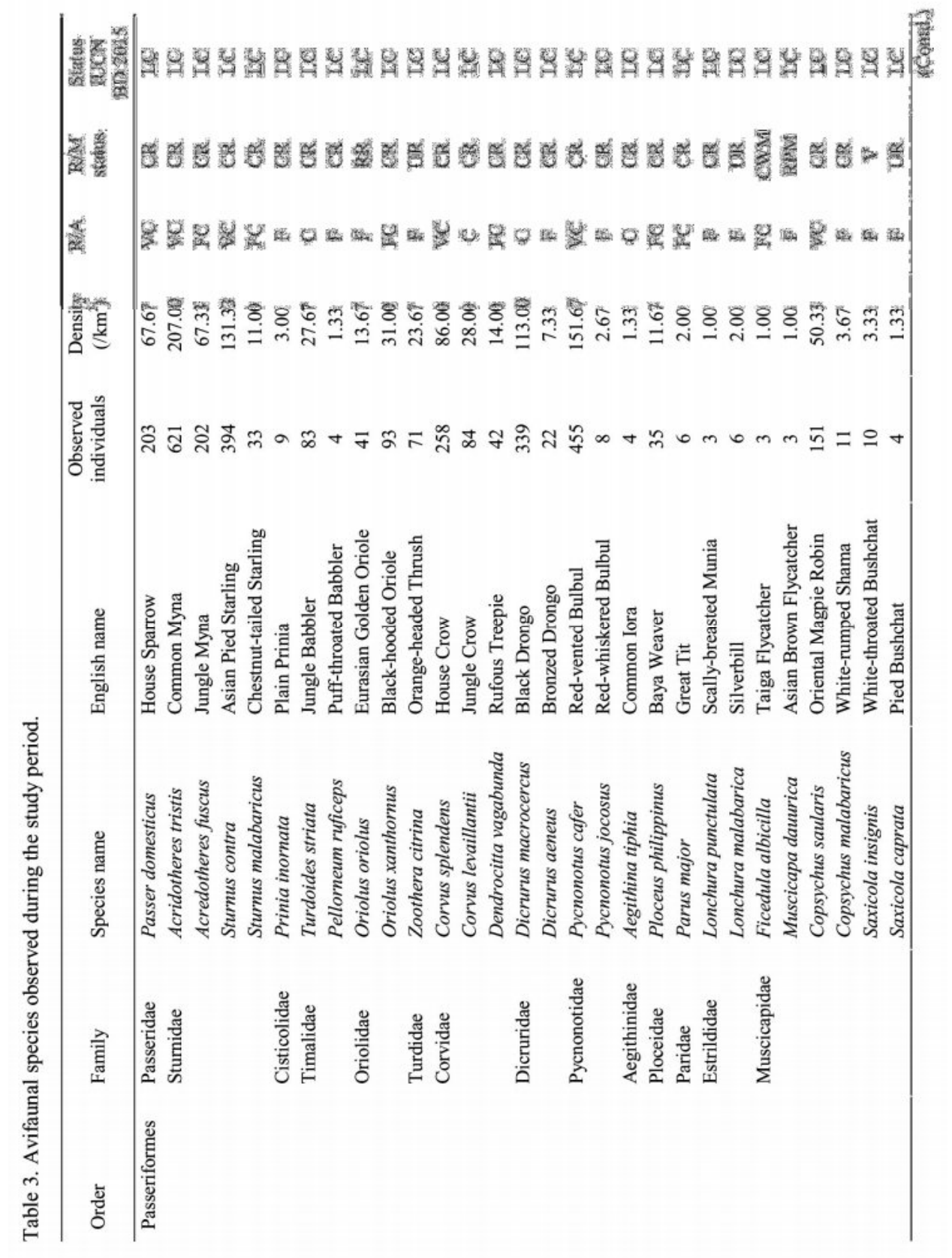




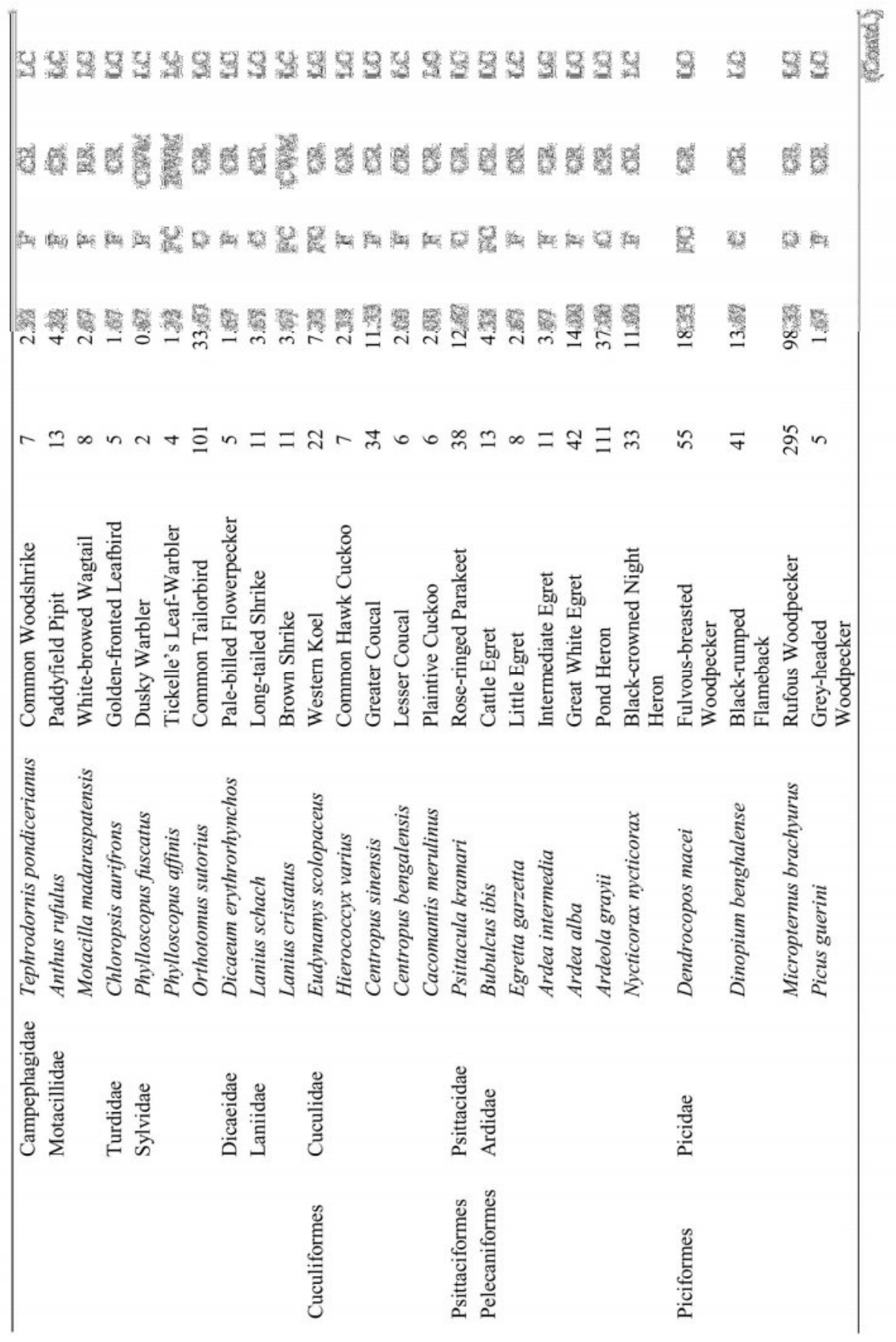




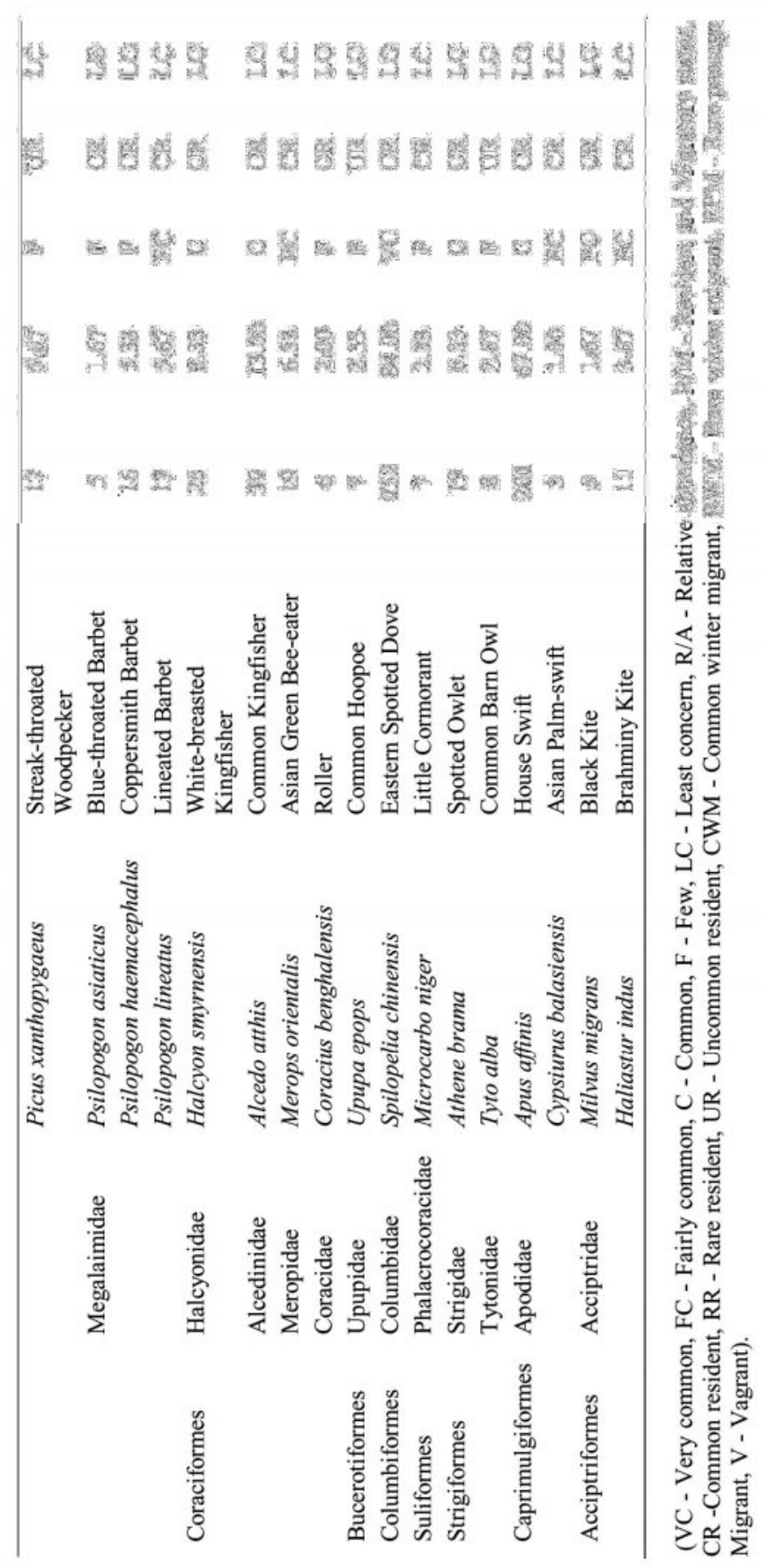




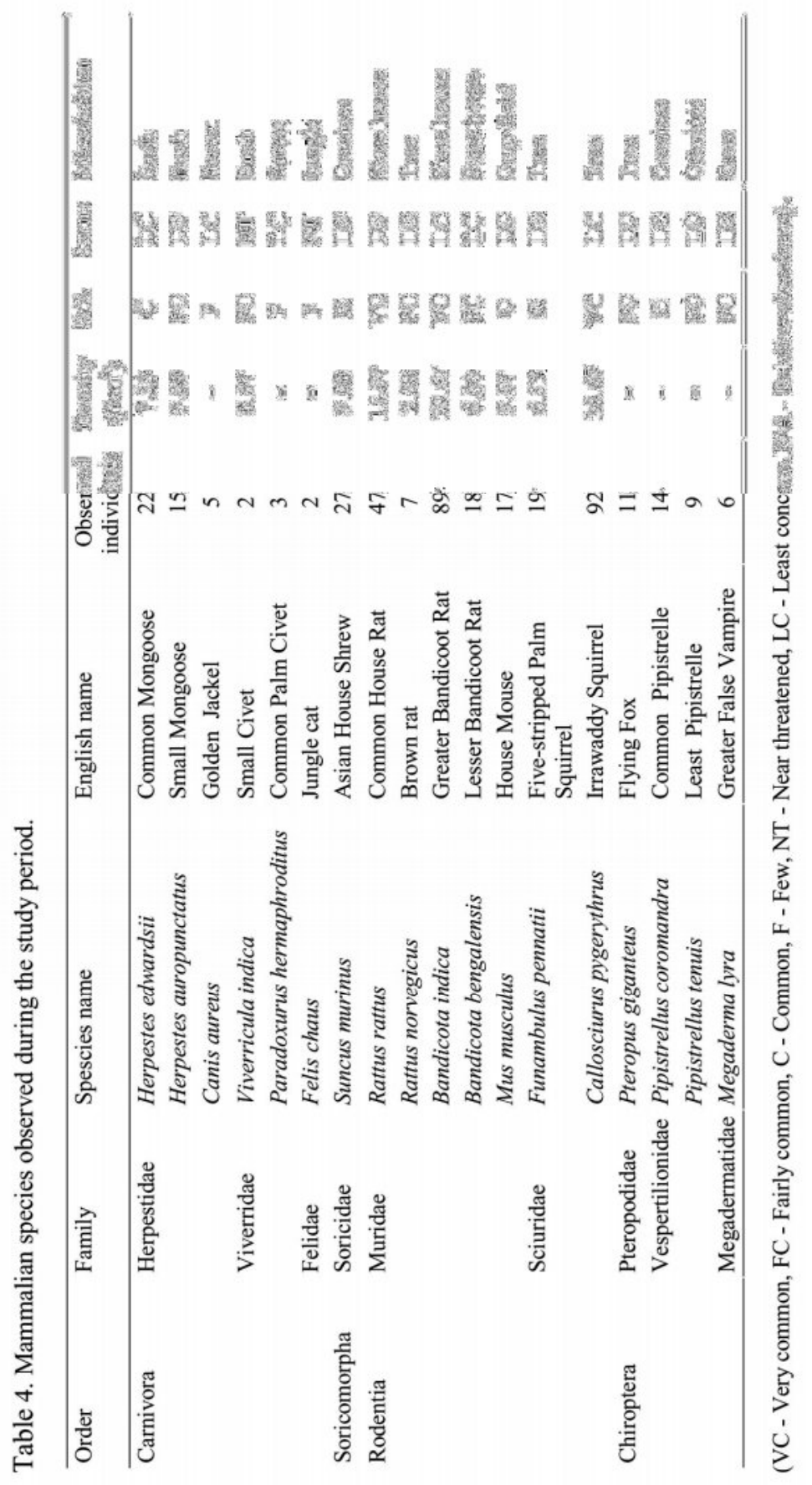


decreased and sustained up to May. Considering season, the highest number of species were found in winter season (102 spp.) followed by summer (76 spp.) and rainy season (63 spp.) (Fig. 2).

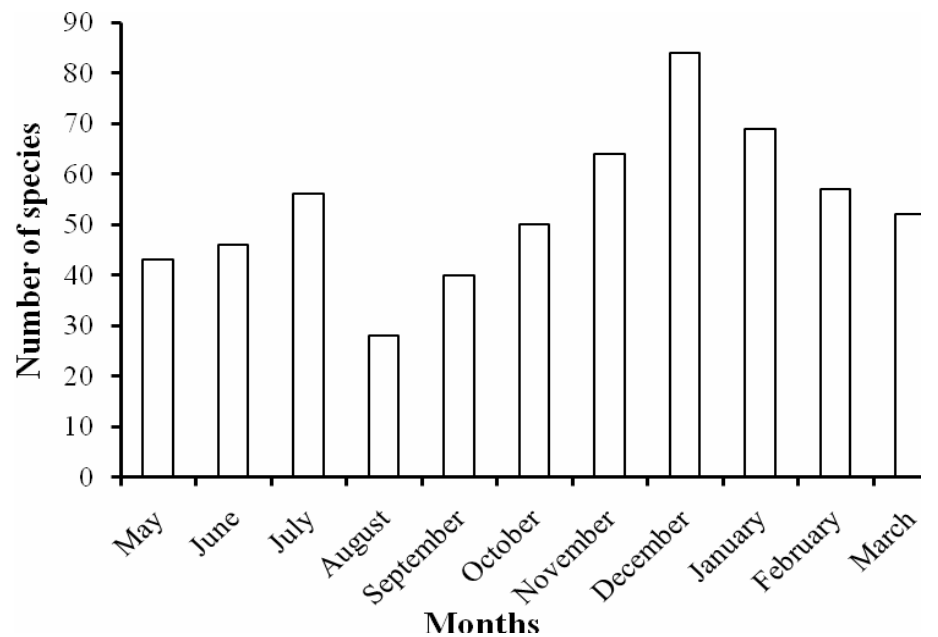

Fig. 2. Monthly variation in the species composition in Kashimpur Union.

The study area was human dominated landscape with enormous number of paddy and other crop fields around. Crop production is generally started in the month of October to December that supports an excessive amount of insects. Thus, insectivorous birds were available in these months. Besides, December is the early month of winter, and some migratory birds visited the area. Hence, number of species was the maximum in winter season. In summer season natural calamities such as storm, cyclone, tornado and hailstorm are often struck in Bangladesh. Probably these natural calamities might affect bird species due to loss of their habitats and paucity of foods in the month of April and May. In rainy season, due to excessive rainfall most of the crop fields and other open areas were inundated with water resulting difficulties to find out the wildlife species in the harsh environment and eventually we found comparatively lower species diversity of wildlife than the other seasons.

Relative abundance and conservation status: The relative abundance of observed wildlife shows that 10 (9.09\%) species were very common, 24 (21.81\%) common, 31 (28.19\%) fairly common and $45(40.91 \%)$ species were few. Among the observed amphibians, 2 $(33.33 \%)$ species were common, $3(50 \%)$ were fairly common and $1(16.67 \%)$ were few. 
Among recorded reptiles, 3 (21.43\%) species were common, 3 (21.43\%) fairly common and $8(57.14 \%)$ were few. Of the birds, $7(9.72 \%)$ species were very common, 14 (19.44\%) common, 17 (23.61\%) fairly common and 34 (47.23\%) species were few. Among the recorded mammals, $3(16.66 \%)$ species were very common, $5(27.77 \%)$ common, 7 (39\%) fairly common and $3(16.66 \%)$ species were few.

According to IUCN Bangladesh (2015a), overall conservation status of recorded wildlife shows that 5 species were near threatened (two mammals and three reptiles) and remaining 105 species were of least concern nationally.

The study area has gradually turned into urban area and this is one of the major causes of habitat loss of wild animals. Sometimes people kill snakes, birds like herons, egrets, jackels, civets and jungle cat unconsciously due to lack of adequate knowledge about the ecosystem services of wildlife.

Resident and migratory status of birds: Regarding the resident and migratory status of birds, 66 (91.62\%) species were resident, $5(7.00 \%)$ migrants and $1(1.38 \%)$ species were vagrant. Among the resident birds, 58 species were common resident, 6 uncommon resident and 2 species were rare resident. Of the 5 migratory birds, 3 species were common winter migrants, one was rare winter migrants, and one was rare passage migrants. Siddiqui et al. (2008) documented in total 176 migratory birds in Bangladesh. This study found diverse microhabitats, plenty of foods and roosting sites both for resdents and migratory birds that facilitated living for these bird species. The area also provided breeding facilities that might be the reason for greater assemblage of resident birds.

Habitat utilization by wildlife: Wildlife utilizes diverse microhabitats in the study area. Of the wildlife recorded in the diverse microhabitats, $20(18.18 \%)$ were seen in the woody plants followed by $17(15.45 \%)$ in tree branches, $12(10.9 \%)$ in the bushes, 11 $(1 \%)$ in the fruiting plants, $8(7.27 \%)$ in the open forest, $8(7.27 \%)$ were seen in the different water bodies (marsh, canal, small river and beel), etc. (Fig. 3). These results indicate that most of the wild animals occurred in the terrestrial habitat probably because of the large insects population was available there as food items for insectivore wild animals. Besides, there were many large fruiting trees, woody and flowering plants which provide food, shelter and nesting facilities for breeding of wildlife in the study area.

Species diversity indices: The calculated diversity indices indicate that the diversity of birds (Simpson's index of diversity D $=0.942$ and Shannon-Wiener Index $H=3.287$ ) was higher than the other groups observed (viz. amphibians, reptilians and mammalians). However, mammals and birds were more evenly distributed (mammals $=0.820$ and birds 
$=0.768$ ) in comparison to amphibians and reptiles (Table 5). Sarker et al. (2000) reported that avian diversity was higher in the cultivated and bushy lands because of food availability and adequate shelter. The study area is enriched with homestead forest and garden, cultivated land, fallow land, water bodies and bushy land. This habitat attracted the birds more than the other groups observed in the study area, hence probably diversity of birds was higher than others wild animals.

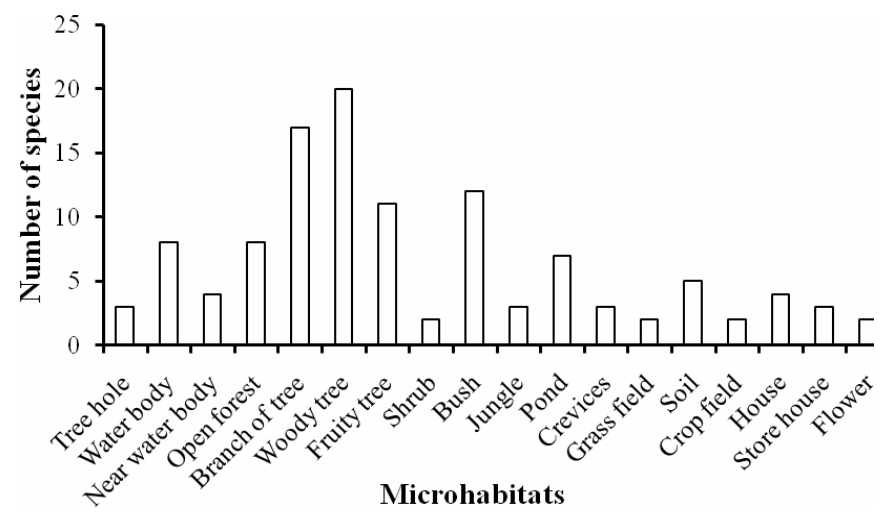

Fig. 3. Number of species found in the different microhabitats.

Table 5. Species diversity indices according to groups.

\begin{tabular}{lcccc}
\hline Parameter & Amphibia & Reptiles & Birds & Mammals \\
\hline Simpson's index of diversity (D) & 0.624 & 0.789 & 0.942 & 0.869 \\
Shannon-Wiener index (H) & 1.214 & 2.008 & 3.287 & 2.370 \\
Evenness (E) & 0.678 & 0.761 & 0.768 & 0.820 \\
\hline
\end{tabular}

Threats and conservation problems: Frequent use of agro-chemicals in the crop fields, urbanization, conversion of fallow and forest land into agricultural land were the main threats for survival of wildlife in the study area. Additionally, illegal hunting, shooting, clearing of thickets, bushes, jungles and logging of homested forest were also noticed during the study period. Dumping of wastes materials, plastics, polythene and chips packets left by human polluted the environment and eventually leading to the unfavorable habitat for wildlife. Recorded wild animals are being affected by encountering these extrinsic problems and threats in the study area.

Conservation awareness and scientific monitoring of wildlife are limited in Bangladesh results 31 species has gone extinct regionally from the country (IUCN Bangladesh 
2015a), and many of them are on the brink of local extinction. Rigorous scientific studies are important to ensure long-term conservation of wildlife and their habitats.

\section{Acknowledgement}

The authors would like to acknowledge the Ministry of Science and Technology as the study was partially funded by the National Science and Technology (NST) fellowship program.

\section{References}

Akash, M., M.A. Hossain, G.W. Chowdhury, H. Mahmud and M.A. Islam. 2013. Status of avifauna in Curzon Hall premises University of Dhaka, Bangladesh. Ecoprint 20: 1-8.

Banglapedia, Ed: Sirajul Islam, 2003, Asiatic Society of Bangladesh.

Banu, M.F.A, M. Akash, G.W. Chowdhury and M.A. Islam. 2016. Status and seasonal occurance of birds in Dhaka University Campus. Dhaka Univ. J. Biol. Sci. 25(1): 27-37.

CBD. 2006. Global Biodiversity Outlook 2. Secretariat of the Convention on Biological Diversity (SCBD), Montreal. $81 \mathrm{pp.}$

CBD. 2007. Biodiversity and Climate Change. Secretariat of the Convention on Biological Diversity, Montreal. 48 pp.

Chowdhury, S., U. Aich and O. Shahadat. 2014. Checklist of avian fauna of Dhaka University Campus, Bangladesh. Int. J. Fauna. Biol. Stud. 1 (5): 56-60.

Daniel, J.C. 2002. The book of Indian reptiles and amphibians. Bombay Natural History Society. Oxford University Press. 238 pp.

Das, A.K. 1975. A study on birds of Curzon Hall and Ramna Park. M.S. thesis (unpubl.), Dept. of Zoology, University of Dhaka.

Grimmett, R., C. Inskipp and T. Inskipp. 1999. Pocket guide to the birds of the Indian subcontinent. Oxford University Press, New Delhi, India. 384 pp.

Halder, R.R. 2010. A phograpic guide to the bird of Bangladesh. Baikal Teal Publication, Dhaka, Bangladesh. $257 \mathrm{pp}$.

Hasan, M.K. and M.M. Feeroz. 2014. Species diversity and habitat preferences of amphibian fauna in six protected areas of Bangladesh. Bangladesh J. Zool. 42(1): 105-116.

Hasan, M.K., M.M.H. Khan and M.M. Feeroz. 2014. Amphibians and reptiles of Bangladesh - A field guide. Arannayk Foundation, Dhaka, Bangladesh.191 pp.

Hossain, M.K., M.F. Jaman and S.U. Sarker. 2004. Diversity of herpeto-mammalian fauna and their conservation issues in Hatiya island, Bangladesh. Tropi. Biod. 8(2):71-78.

Hussain, K.Z., A.R. Khan and S.U. Sarker. 1974. Birds of Dhaka. Bangladesh J. Zool. 2(2): 153170.

Islam, M.S., O. Shahadat, M.M. Kabir, M.A. Rashid, H.A. Razi, M. Kamaruzzaman, S.M.I. Alam, T. Mustafa and M.S. Islam. 2014. Avifauna of the national botanical garden of Bangladesh. $J$. Taxon. and Biod. Res. 6: 17-20.

IUCN Bangladesh. 2015a. Red List of Bangladesh: A Brief on Assessment Result. Volume 1: IUCN, International Union for Conservation of Nature, Bangladesh Country Office, Dhaka, Bangladesh, pp. 24.

IUCN Bangladesh. 2015b. Red List of Bangladesh Vol. 2: Mammals. IUCN, International Union for Conservation of Nature, Bangladesh Country Office, Dhaka, Bangladesh, pp. xvi+232. 
IUCN Bangladesh. 2015c. Red List of Bangladesh Vol. 3: Birds. IUCN, International Union for Conservation of Nature, Bangladesh Country Office, Dhaka, Bangladesh, pp. xvi+676.

IUCN Bangladesh. 2015d. Red List of Bangladesh Volume 4: Reptiles and Amphibians. IUCN, International Union for Conservation of Nature, Bangladesh Country Office, Dhaka, Bangladesh, pp. xvi+320.

Jaman, M. F., M.S. Majumder, M.S. Hossain, M.M. Rahman and M. Uddin. 2014. Diversity of Wildlife at Ruhitpur Union, Keraniganj, Dhaka. J. Asiat. Soc. Bangladesh, Sci. 40 (2): 295308.

Jaman, M.F., M. Uddin, M.M. Alam, M.M. Rahman, M.T. Khatun and S.M.I. Alam. 2015. Species diversity and population status of wildlife in Keshabpur, Bangladesh. J. Biodiv. Con. and Biores. Manage. 1(2): 9-21.

Jaman, M.F., S.U. Sarker and N.J. Sarker. 1999. Food habits and feeding behavior of black drongo, Dicrurus macrocercus albirictus (Hodgson). Bangladesh J. Zool. 26(2): 5766.

Karmakar, S., S. Parween and A.M.S. Reza. 2011. Birds of Joypurhat district, Bangladesh. J. L. Sci. 6: 51-57.

Khan, M.A.R. 1982. Wildlife of Bangladesh (A checklist). University of Dhaka. Dhaka. 173 pp.

Khan, M.A.R. 2015. Wildlife of Bangladesh-checklist and guide. Chayabithi, Purana Paltan, Dhaka 1000. $568 \mathrm{pp}$.

Khan, M.M.H. 2008. Protected Areas of Bangladesh - A. Guide to Wildlife. Nishorgo Support Program, Bangladesh. Forest Department. 304 pp.

Khan, S.I. and M.F. Ahsan. 2011. Birds of the Madhupur National Park, Bangladesh. Bangladesh J. Zool. 39(1): 49-63.

Koziell, I. 2001. Diversity not Adversity: Sustaining Livelihoods with Biodiversity. International Institute for Environment and Development (IIED) and Department for International Development (DFID), England. 58 pp.

Mittermeier, R.A., N. Myers, J.B. Thomsen, G.A. Da Fonseca and S. Olivieri. 1998. Biodiversity hotspots and major tropical wilderness areas: approaches to setting conservation priorities. Conserv. Biol. 12: 516-520.

Mohsanin, S. and M.M.H. Khan. 2009. Status and seasonal occurance of birds in Jahanginnagar University Campus, Bangladesh. Bangladesh J. L. Sci. 21(1): 29-37.

Rahman, M. S., S. U. Sarker and M. F. Jaman. 2012. Ecological status of the herpeto-mammalian fauna of the Padma River and its adjacent areas, Rajshahi and their conservation issues. Bangladesh J. Zool. 40(1): 135-145.

Rajia, S., M.M. Alam, G.W. Chowdhury, M. Akash and M.A. Islam. 2015. Status and diversity of birds of Ramna Park, Dhaka, Bangladesh. Bangladesh J. Zool. 43(2): 291-301.

Sarkar, N.J., D. Sultana, M.F. Jaman and M.K. Rahman. 2009. Diversity and population of avifauna of two urban sites of Dhaka, Bangladesh. Ecoprint. 16:1-7.

Sarker, S.U., M.F. Jaman, N.J. Sarker and M.K. Hossain. 2000. Status of wildlife of St. Martins Island, Bangladesh. Dhaka Univ. J. Biol. Sci. 9(1): 75-85.

Shannon, C.E. and W. Wiener. 1949. The mathematical theory. University of Illinois press, Urbana. $117 \mathrm{pp}$.

Siddiqui, K.U., M.A Islam, Kabir, S.M.H., M. Ahmad, A.T.A. Ahmed, A.K.A. Rahman, E.U. Haque, Z.U. Ahmed, Z.N.T. Begum, M.A. Hasan, M. Khondker and M.M Rahman (eds.). 2008. Encyclopedia of flora and fauna of Bangladesh, Vol. 26. Birds. Asiatic Society of Bangladesh, Dhaka. 632 pp.

Simpson, E. H.1949. Measurement of diversity. Nature 163: 688.

(Revised copy received on 1.7.2018) 